\title{
Spontaneous Hemorrhage of a Spinal Ependymoma in the Filum Terminale Presenting with Acute Cauda Equina Syndrome: Case Report
}

\author{
Tohru Terao, ${ }_{1}^{1}$ Naoki Kato, ${ }^{1}$ Takuya Ishii, ${ }^{1}$ Keisuke Hatano, ${ }^{1}$ Hideaki Takeishi, ${ }^{1}$ Shota Kakizaki, ${ }^{1}$ Satoshi Tani, ${ }^{2}$ \\ and Yuichi Murayama ${ }^{2}$
}

\begin{abstract}
We present a rare case of spontaneous hemorrhage of a spinal ependymoma in the filum terminale presenting with acute cauda equina syndrome. A 16-year-old male presented with a sudden onset of severe back pain that began 10 days before hospitalization. This symptom progressed, followed by development of decreased sensation in the lower extremities, bladder dysfunction, and motor weakness that advanced to an inability to walk. Spinal magnetic resonance imaging revealed a hemorrhagic mass from Th12 to L2 and L4 to L5, and clinical signs indicated acute cauda equina compression. One day after admission to the hospital, emergency surgery was performed. A spinal tumor in the conus portion with a spinal subarachnoid hemorrhage was seen. Gross total excision of the massive hematoma mixed with the underlying tumor was performed. Pathological findings of the excised tumor demonstrated a WHO Grade II cellular ependymoma of the non-myxopapillary type. The patient made a significant recovery. The ability to walk was restored, and impaired bladder function improved at follow-up. Early diagnosis and suitable treatment are associated with a more favorable outcome.
\end{abstract}

Keywords: filum terminale, ependymoma, subarachnoid hemorrhage, lumbar spine

\section{Introduction}

An ependymoma rarely presents with acute neurological decline after spontaneous hemorrhage. ${ }^{1)}$ Previously, some cases of acute compression due to hemorrhages into ependymomas in the lumbar spine have been reported. ${ }^{2-12)}$ In particular, typical presentation of ependymoma, which appears at the conus medullaris and filum terminale, includes cauda equina syndrome involving severe lower back pain, lower extremity paresthesias, lower extremity weakness, and bladder dysfunction. ${ }^{13,14)}$ Immediate surgical treatment may be performed for symptomatic improvement. In a previous study, some spinal ependymoma cases experienced a long delay in diagnosis. ${ }^{15-18)}$ We report a spontaneous hemorrhage of a filum terminale ependymoma presenting with acute cauda equina syndrome. This patient underwent immediate surgical

\footnotetext{
${ }^{1}$ Department of Neurosurgery, Atsugi City Hospital, Atsugi, Japan ${ }^{2}$ Department of Neurosurgery, The Jikei University School of Medicine, Tokyo, Japan
}

Received: December 8, 2015; Accepted: February 29, 2016 decompression and resection with neuromonitoring. The patient demonstrated immediate improvement in the neurologic deficits. Ambulation without assistance was restored, and bladder function recovered to normal.

\section{Case Report}

A 16-year-old male was referred to another hospital 2 days after sudden onset of severe back pain. The patient had no history of intake of anticoagulation and/or antiplatelet agents. The back pain continued to progress, followed by the development of decreased sensation in the lower extremities and subsequent motor weakness that advanced to an inability to walk. Ten days after onset, he was transferred to our hospital. At this time, he presented with a high-grade fever over $38^{\circ} \mathrm{C}$ that may have been induced by a urinary tract infection caused by urine retention. Also, he experienced sphincter dysfunction with decreased rectal tone. A $\mathrm{T}_{1}$-weighted image $\left(\mathrm{T}_{1} \mathrm{WI}\right)$ from lumbar magnetic resonance imaging (MRI) showed an iso-hypointense area extending from the Th12L1 disc to the distal endplate of the L2 vertebral body (Fig. 1a). The conus was not visualized. In addition, a relatively hyperintense area that was suggestive of fluid collection was seen from the level of the L4-S1 vertebral body. A $\mathrm{T}_{2}$-weighted image $\left(\mathrm{T}_{2} \mathrm{WI}\right)$ also demonstrated a strongly hypointense area compared to $\mathrm{T}_{1} \mathrm{WI}$ from the L1-2 disc to the distal endplate of the L2 vertebral body (Fig. 1b). The high-intensity lesion on $\mathrm{T}_{1} \mathrm{WI}$ was of low intensity on $\mathrm{T}_{2} \mathrm{WI}$ and extended from L4 to S1, suggesting hemorrhagic intradural fluid collection. The area demonstrated a low-intensity area on $\mathrm{T}_{1} \mathrm{WI}$ at $\mathrm{Th} 12$ to $\mathrm{L} 2$ that showed heterogeneous enhancement with gadolinium DTPA (Fig. 1c, d). Acute cauda equina compression syndrome as a consequence of spinal tumoral hemorrhage that progressed to rapid neurologic deterioration was diagnosed. One day after admission, surgery was performed with monitoring of transcranial motor-evoked potential and somatosensory-evoked potential by the stimulation of the tibial nerve and direct bipolar stimulation of the intradural cauda equina nerve. A laminectomy of the lower half at Th12 and an osteoplastic laminotomy from L1 to L2 were performed. After a dural incision, a subarachnoid hemorrhagic (SAH) mass was seen that compressed the cauda equina nerve to the ventral side (Fig. 2a). This hemorrhagic mass extended from the conus medullaris down to the level of L2 (Fig. 2b). After the blood clot was removed, a non-hemorrhagic grayish soft tumor was observed in the conus portion (Fig. 2c). Using a cavitational ultrasonic surgical aspirator, gross total resection (GTR) of 

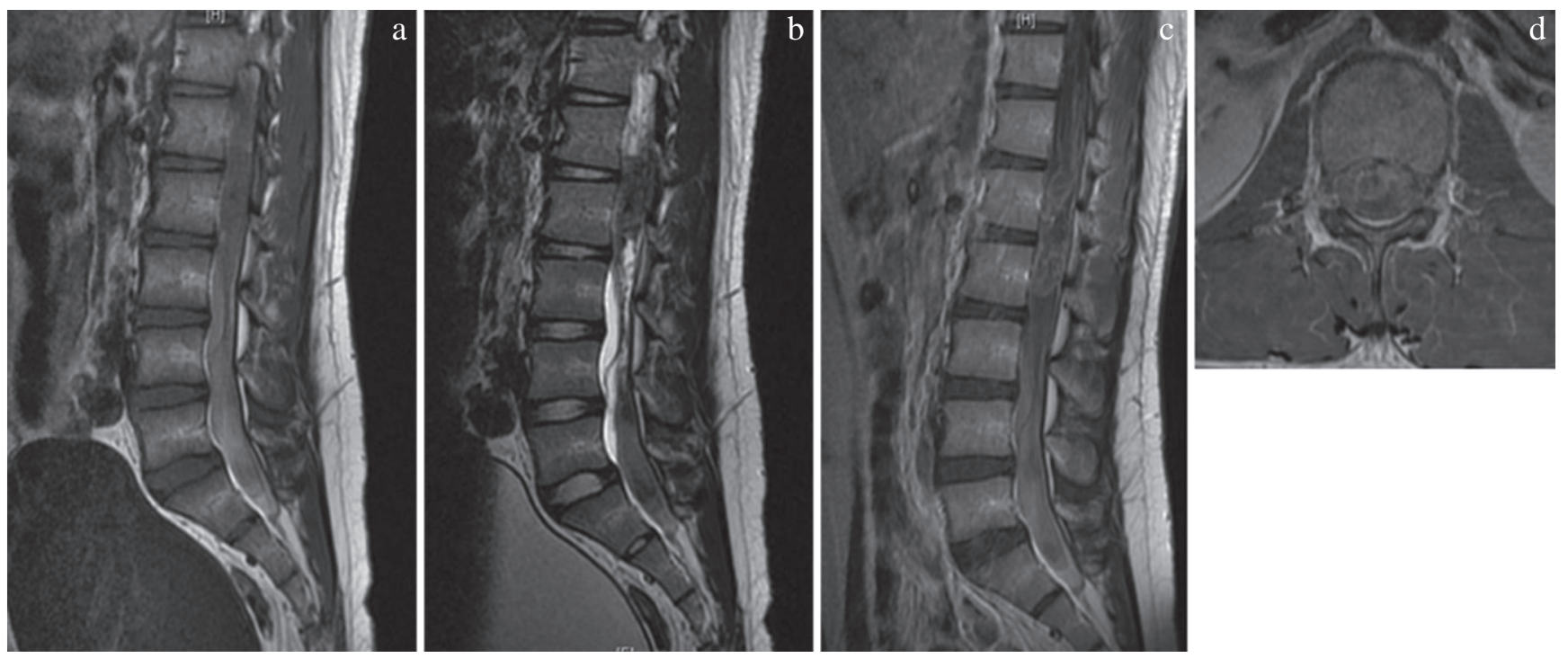

Fig. 1 a-d: Pre-operative sagittal MRI of the lumbar spine. (a) $A T_{1}$-weighted image $\left(\mathrm{T}_{1} \mathrm{WI}\right)$ shows an iso-hypointense area extending from the Th12-L1 disc to the distal endplate of the L2 vertebral body. The conus is not visualized. The relatively hyperintense area that was suggestive of fluid collection is seen from the level of the L4 to the $\mathrm{S} 1$ vertebral body. (b) $\mathrm{A} \mathrm{T}_{2} \mathrm{WI}$ also demonstrates strong hypointensity of the area from the L1-2 disc to the distal endplate of the L2 vertebral body. The image showed a distinct, well-circumscribed area that was suggestive of hemorrhage. The relatively hyperintense lesion seen from the level of the L4 to the S1 vertebral body on $\mathrm{T}_{1} \mathrm{WI}$ was seen at low intensity on $\mathrm{T}_{2} \mathrm{WI}$. (c) Sagittal $\mathrm{T}_{1} \mathrm{WI}$ with gadolinium enhancement showed an irregular enhancing mass from the Th11-Th12 disc to the distal endplate of the L2 vertebral body. (d) Axial $\mathrm{T}_{1} \mathrm{WI}$ with gadolinium enhancement showed the intradural enhanced mass at the level of the L1 vertebral body on the ventral side. Hence, from the radiologic findings, we considered an underlying tumor in addition to a hematoma.

the mass was performed using the microscopic technique. After surgical resection of the hematoma mixed with the underlying tumor, the cauda equina nerve was visualized (Fig. 2d). The lamina of Th12 and L1 that had been removed was returned and affixed in the normal position using a mini-plate.

On histopathological examination, the mass showed perivascular rosettes and ependymal cells, indicating a WHO Grade II cellular ependymoma of the non-myxopapillary type (Fig. 3). We found no features that are unique to the myxopapillary subtype, such as mucin or elongated tumor cells arranged in a papillary manner. The Ki67 labeling index was around $7 \%$.

Post-operative MRI demonstrated GTR of the mass including the tumor and blood clot (Fig. 4). Post-operatively, the patient was able to ambulate without difficulty. His sphincter function also recovered. The patient was discharged to an inpatient rehabilitation unit. At the 4-month follow-up in this unit, his lower limbs were much stronger, allowing rehabilitation to walk long distances. In addition, the sensory deficits completely resolved. Presently, at 17 months after surgery, no recurrence of the tumor has been observed with radiological evaluation, and his neurological condition remains normal.

\section{Discussion}

The incidence of ependymomas among all spinal tumors is between 1.5 and 5\%, ${ }^{19-22)}$ and over half of these occur in the conus medullaris or filum terminale. ${ }^{13,14,19)}$ Almost all ependymomas of the filum terminale or conus medullaris are of the myxopapillary variant, ${ }^{14,22)}$ which has the greatest tendency to bleed of all subtypes of ependymomas. ${ }^{23)}$ Fourteen reports have been published of 15 patients including our case with acute neurological deterioration after hemorrhage into a spinal ependymoma (Table 1). ${ }^{5-11,14,24-27)}$ The average age in that study was 34.9 (15-65) years, and so our case of a 16-year-old was too young to compare to the reviewed cases. In this review of reported cases, four of 15 patients had a WHO Grade II ependymoma of the non-myxopapillary subtype including the papillary, tanycytic, and cellular variants as was seen with our case. Tait et al. ${ }^{14)}$ reported that the bleeding rate of non-myxopapillary subtypes is $\sim 30 \%$ of all reported cases of SAH arising from any type of ependymoma of the filum terminale or conus medullaris. Fincher ${ }^{28)}$ proposed that the clinical characteristics of primary spinal tumors presenting with SAH are severe back pain and headache, accompanied by bloody cerebrospinal fluid. In our review, 10 of 15 including our case presented with severe back pain as the first symptom.

In our case, distinguishing whether the tumor originated from the conus medullaris or filum terminale was difficult. The intraoperative view showed blood clots adjacent to the tumor in the subarachnoid space that extended from the conus portion down to the level of L2. During surgery, after the blood clot was removed, a grayish neoplastic mass in the conus portion was evident and was extracted without incising the conus medullaris. Postoperatively, the patient's bladder and rectal dysfunctions recovered. Thus, we speculated that the ependymoma originated within the filum terminale and bordered with the conus medullaris.

Early diagnosis and suitable treatment were associated with a more favorable outcome for spinal ependymomas. ${ }^{16,29,30)}$ 


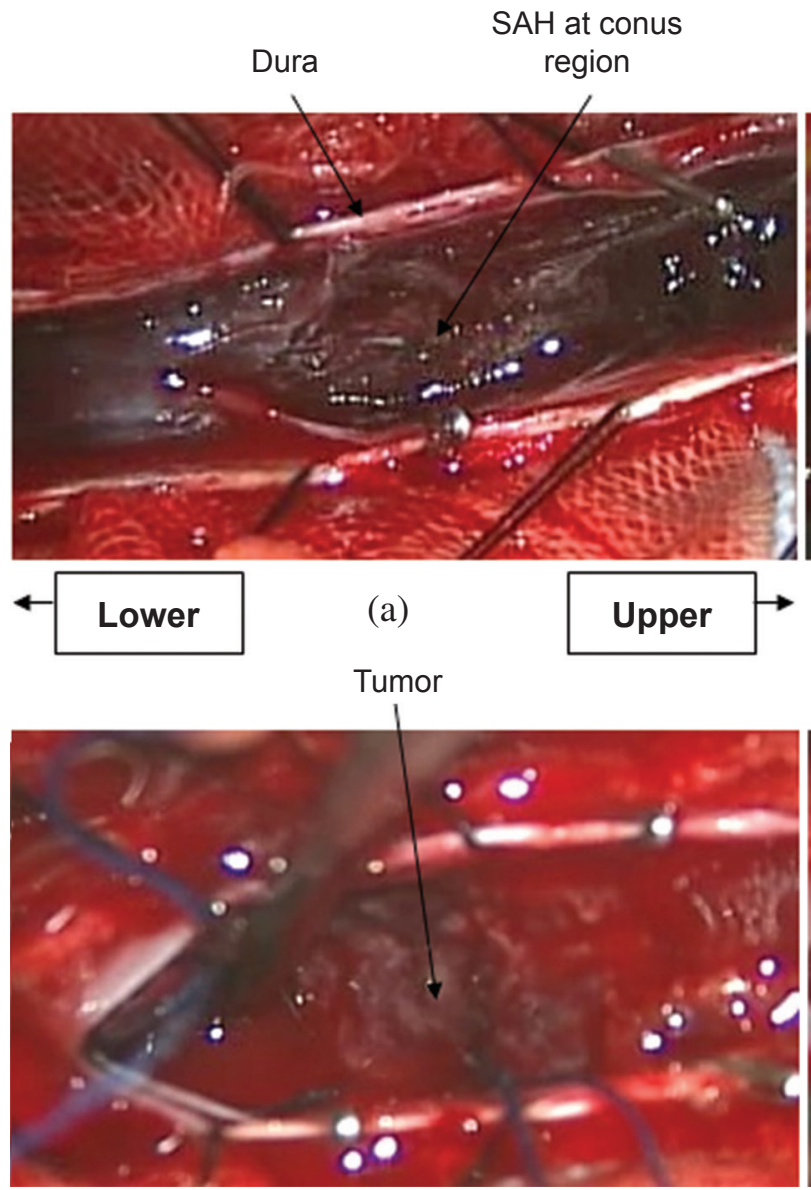

(c)

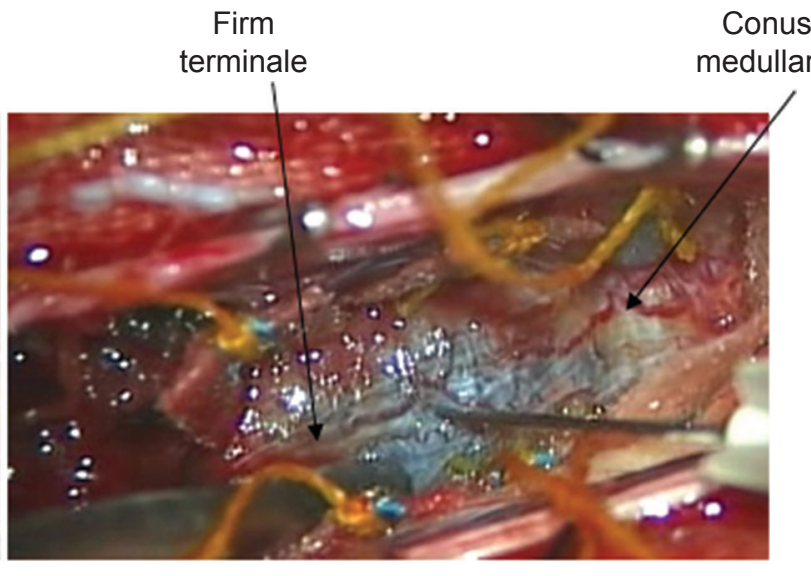

(b)

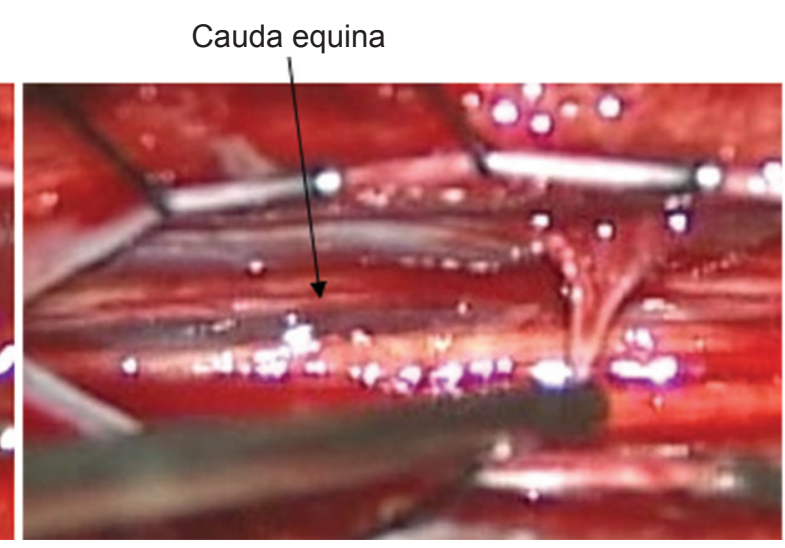

(d)

Fig. 2 Intraoperative findings (a) After the dural incision, a subarachnoid hemorrhagic mass was seen. (b) A blood clot mass mixed with an underlying tumor was visualized that extended from the conus medullaris down to the level of L2. (c) After the blood clot was removed, a non-hemorrhagic grayish soft tumor was observed. (d) After surgical resection of the hematoma mixed with the underlying tumor, the cauda equina nerve was visualized.
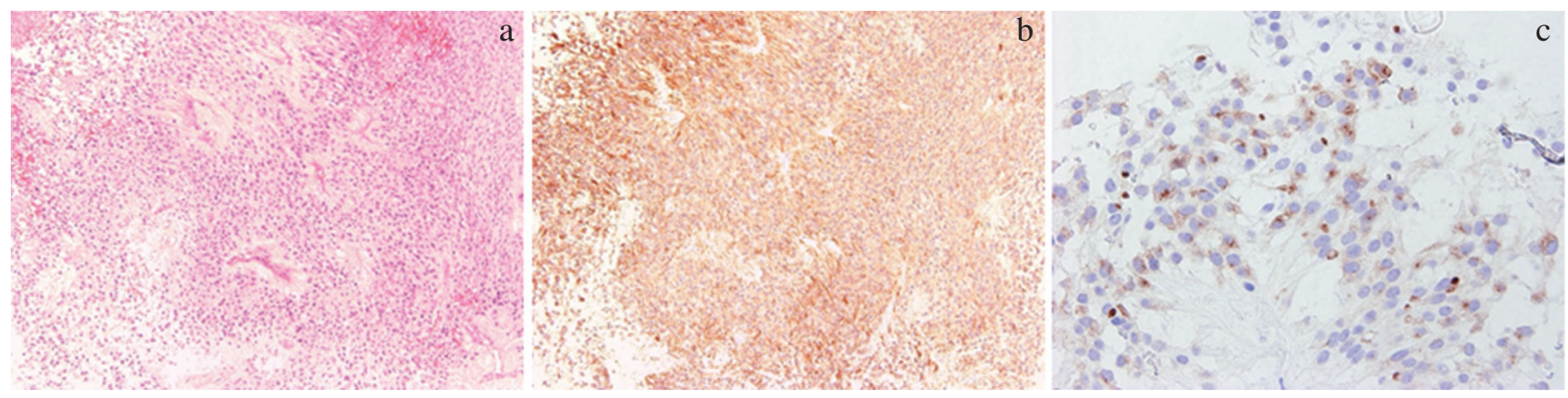

Fig. 3 Histopathological findings of the tumor. Hematoxylin-eosin staining $(a, \times 10)$ shows perivascular pseudorosettes and tapering processes of neoplastic cells around a central blood vessel. Tumor cells with eosinophilic cytoplasm formed various tubular structures surrounding the vessels. Immunohistochemical staining is positive for glial fibrillary acid protein $(b, \times 10)$ and EMA $(c, \times 40)$. These characteristic features indicates a diagnosis of ependymoma. We found no features that are unique to the myxopapillary subtype such as mucin or elongated tumor cells arranged in a papillary manner.

However, in previous reports, some patients with an acute decline after hemorrhage into an ependymoma had a significant delay before surgical decompression. ${ }^{1,5)}$ Heuer et al. ${ }^{1)}$ reported two of their cases and reviewed nine previously reported cases of lumbar spine ependymomas presenting with acute hemorrhage and resulting in acute neurological decline. ${ }^{5-8,10,14)}$ In the review by Heuer et al., ${ }^{1)}$ four patients underwent emergency surgical decompression, and three underwent a delayed operation. Regarding the post-operative course, in the patients who underwent emergency surgery, preoperative motor dysfunction tended to recover, but symptoms of sphincter dysfunction were associated with a poor outcome. 

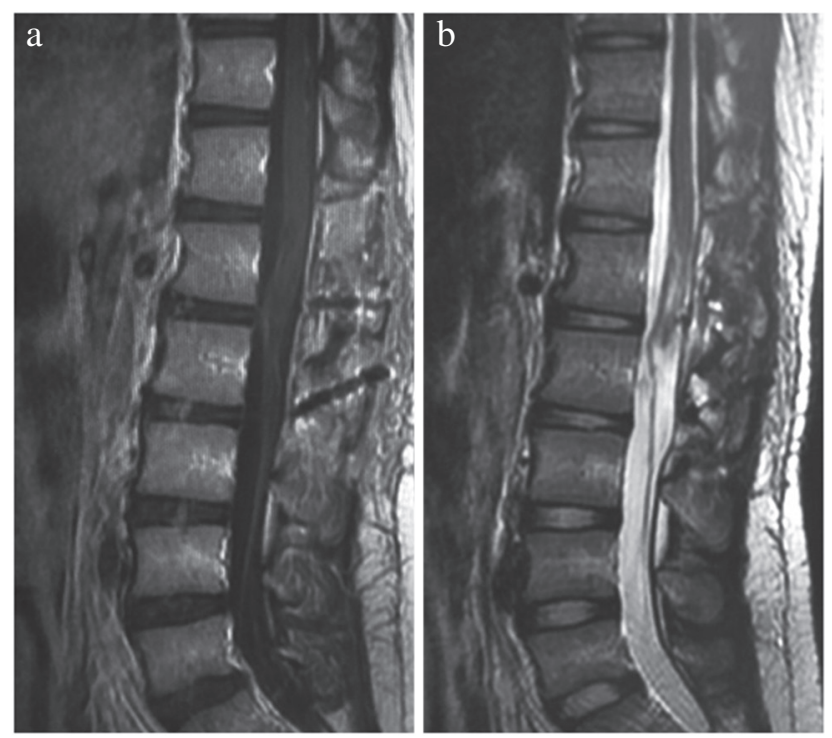

Fig. 4 Post-operative MRI of the lumbar spine. (a) Sagittal $\mathrm{T}_{1}$ WI with gadolinium enhancement shows the disappearance of the contrast radiography lesion recognized pre-operatively. (b) The conus is visualized on sagittal $\mathrm{T}_{2} \mathrm{WI}$, which demonstrate resection of the tumor mass and the hemorrhage.
Heuer et al. ${ }^{1)}$ proposed that extensive adhesions present in patients with delayed treatment for tumor resection makes the operation too difficult. In our case, 11 days elapsed from the acute decline after hemorrhaging into the ependymoma to the surgical decompression. So, our surgery was performed immediately on the day after hospitalization, and he made a significant recovery including the return of bladder function despite this delay. With the purpose of preserving the neural and skeletal structure as much as possible, meticulous microsurgical resection during careful monitoring of transcranial motor-evoked potential, somatosensory-evoked potential, and bipolar stimulation of the intradural cauda equina nerve was performed, followed by osteoplastic laminotomy. After resection of the blood clot and neoplastic mass at the conus portion, the lamina that had been removed was returned to the former position to preserve the physiological structure with the intention of not obstructing the patient's development and growth.

The role of postoperative radiotherapy in spinal ependymoma to prevent the development of cerebrospinal fluid dissemination is not clear, and no consensus exists. Nakamura et al ${ }^{31)}$ reviewed 25 cases of myxopapillary ependymomas of the cauda equina treated surgically between 1972 and 2005 . In this study, 14 of 15 patients who achieved total resection

Table 1 Literature review of 15 patients with acute neurological deterioration after hemorrhage into a spinal ependymoma

\begin{tabular}{|c|c|c|c|c|c|c|c|c|}
\hline $\begin{array}{l}\text { Author } \\
\text { published years }\end{array}$ & Age & Sex & First symptom & Spinal level & $\begin{array}{l}\text { Timing of } \\
\text { surgery }\end{array}$ & Tumor location & Pathology & Outcome \\
\hline Destee et al. ${ }^{5)} 1984$ & 47 & M & Low back pain & $\mathrm{L} 5 / \mathrm{S} 1$ & Delay & Extramedullar & ND & Normal neurology \\
\hline Herb et al. ${ }^{6} 1990$ & 63 & M & Sciatica & L3 & Emergency & Extramedullar & ND & No improvement \\
\hline Rivierez et al. ${ }^{11)} 1990$ & 18 & $\mathrm{~F}$ & Sciatica & L1-L5 & ND & ND & ND & ND \\
\hline Malbrain et al. ${ }^{8)} 1994$ & 65 & $\mathrm{~F}$ & Low back pain & L2-L3 & Emergency & Extramedullar & Myxopapillary & No improvement \\
\hline Lagares et al. ${ }^{7)} 2000$ & 24 & M & Low back pain & Low dorsal & Emergency & Intramedullar & *WHO Grade II & $\begin{array}{l}\text { Ambulating with } \\
\text { assistance }\end{array}$ \\
\hline Oertel et al. ${ }^{10)} 2000$ & 35 & M & paraplegia & Th9-Th11 & Emergency & Intramedullar & *WHO Grade II & $\begin{array}{l}\text { Ambulating without } \\
\text { assistance }\end{array}$ \\
\hline Tait et al. ${ }^{14)} 2004$ & 57 & $\mathrm{~F}$ & $\begin{array}{l}\text { Cauda equine } \\
\text { syndrome }\end{array}$ & L3 & Emergency & Extramedullar & *WHO Grade II & $\begin{array}{l}\text { Ambulating without } \\
\text { assistance }\end{array}$ \\
\hline Heuer et al. ${ }^{1)} 2007$ & $\begin{array}{l}31 \\
31\end{array}$ & $\begin{array}{l}\mathrm{F} \\
\mathrm{M}\end{array}$ & $\begin{array}{l}\text { Low back pain } \\
\text { Low back pain }\end{array}$ & $\begin{array}{l}\text { L1-S2 } \\
\text { Th11-L2 }\end{array}$ & $\begin{array}{l}\text { 1-month delay } \\
13 \text { days delay }\end{array}$ & $\begin{array}{l}\text { Extramedullar } \\
\text { Extramedullar }\end{array}$ & $\begin{array}{l}\text { Myxopapillary } \\
\text { Myxopapillary }\end{array}$ & $\begin{array}{l}\text { Ambulating without } \\
\text { assistance in both cases }\end{array}$ \\
\hline $\begin{array}{l}\text { Martinez-Perez } \\
\text { et al. }{ }^{24)} 2012\end{array}$ & 32 & M & Low back pain & $\begin{array}{l}\text { Th9 \& } \\
\text { L2-L3 }\end{array}$ & Emergency & Extramedullar & Myxopapillary & $\begin{array}{l}\text { Ambulating without } \\
\text { assistance }\end{array}$ \\
\hline Nozaki et al.') 2013 & 23 & M & Low back pain & L1-L2 & 37 days delay & Extramedullar & Myxopapillary & Normal neurology \\
\hline Nicastro et al. ${ }^{25)} 2013$ & 41 & M & $\begin{array}{l}\text { Severe thunderclap } \\
\text { headache }\end{array}$ & C7-Th10 & ND & $\begin{array}{l}\text { Intra and Extra- } \\
\text { medullar }\end{array}$ & anaplastic (Grade III) & Normal neurology \\
\hline $\begin{array}{l}\text { Khalatbari et al. }{ }^{26)} \\
2014\end{array}$ & 15 & M & $\begin{array}{l}\text { Low back pain } \\
\text { paraparesis } \\
\text { urinaryretention }\end{array}$ & L1 & Emergency & Intramedullar & Myxopapillary & $\begin{array}{l}\text { Ambulating without } \\
\text { assistance }\end{array}$ \\
\hline Tonogai et al. ${ }^{27)}$ & 26 & $\mathrm{~F}$ & Low back pain & $\mathrm{L} 1-\mathrm{L} 2 / 3$ & ND & Extramedullar & Myxopapillary & $\begin{array}{l}\text { Ambulating with } \\
\text { assistance }\end{array}$ \\
\hline Our case 2015 & 16 & M & Low back pain & Th12-L2 & 11 days delay & Extramedullar & *WHO Grade II & $\begin{array}{l}\text { Ambulating without } \\
\text { assistance }\end{array}$ \\
\hline
\end{tabular}


followed by whole brain and spinal cord radiation or local irradiation survived without tumor recurrence during a mean postoperative follow-up period of 10.4 years. Nakamura et al. ${ }^{31)}$ concluded that the extent of surgery and the amount of postoperative radiation may be crucial factors in determining the prognosis of patients with myxopapillary ependymoma. Feldman et al. ${ }^{32)}$ reviewed 28 articles describing a total of 475 patients with spinal myxopapillary ependymomas and reported the extent of resection and whether adjuvant radiotherapy was effective. When comparing the recurrence rates in patients who underwent GTR and subtotal resection (STR), the overall recurrence rates were 15.5 and $32.6 \%$, respectively, regardless of whether the patients underwent adjuvant radiotherapy. The total recurrence rate among patients who underwent GTR plus adjuvant radiotherapy was $15.6 \%$, similar to the $15.9 \%$ of patients who underwent GTR alone. The total recurrence rate in patients who underwent STR and radiotherapy was $29.3 \%$, and was $35.1 \%$ in those who underwent STR alone. From these results, GTR alone is associated with decreased recurrence rates compared with STR with or without radiotherapy. In our case, GTR was achieved, and the patient was managed without adjuvant radiotherapy. His pathology was WHO Grade II cellular ependymoma, and the Ki67 labeling index was around 7\%. The optimal surgical and/or adjuvant treatment provides maximal tumor control. Thus, in our case, postoperative radiotherapy should be performed promptly if signs of radiological recurrence including the development of cerebrospinal fluid dissemination appear.

Spontaneous hemorrhage of filum terminale ependymomas is rare but occurs in acute cauda equina syndrome. Recognition of these characteristics can prevent delayed surgery, which reduces the possibly of neurological recovery.

\section{Conflicts of Interest Disclosure}

The authors have no personal, financial, or institutional interest in any of the drugs, materials, or devices used in this study.

\section{References}

1) Heuer GG, Stiefel MF, Bailey RL, Schuster JM: Acute paraparesis from hemorrhagic spinal ependymoma: diagnostic dilemma and surgical management. Report of two cases and review of the literature. J Neurosurg Spine 7: 652-655, 2007

2) Admiraal P, Hazenberg GJ, Algra PR, Kamphorst W, Wolbers JG: Spinal subarachnoid hemorrhage due to a filum terminale ependymoma. Clin Neurol Neurosurg 94: 69-72, 1992

3) Andre-Thomas F, Schaeffer H, de Martel T: Syndrome d'hemorragie realsise par une tumeur de la queue de cheval. Paris Med 77: 292-296, 1930

4) Argyropoulou PI, Argyropoulou MI, Tsampoulas C, Gogos P, Manavis I, Efremidis SC: Myxopapillary ependymoma of the conus medullaris with subarachnoid haemorrhage: MRI in two cases. Neuroradiology 43: 489-491, 2001

5) Destée A, Lesoin F, Warot M, Mendolia G, Devos P, Warot P: Tumoral spinal meningeal hemorrhage during anticoagulant treatment. Rev Neurol (Paris) 140: 517-519, (Fr), 1984

6) Herb E, Schwachenwald R, Nowak G, Müller H, Reusche E: Acute bleeding into a filum terminale ependymoma. Neurosurg Rev 13: 243 245, 1990

7) Lagares A, Rivas JJ, Lobato RD, Ramos A, Alday R, Boto GR: Spinal cord ependymoma presenting with acute paraplegia due to tumoral bleeding. J Neurosurg Sci 44: 95-98, 2000
8) Malbrain ML, Kamper AM, Lambrecht GL, Hermans P, Baeck E, Verhoeven F, Wyffels G, Verbraeken H: Filum terminale ependymoma revealed by acute cauda equina compression syndrome following intratumoral and spinal subarachnoid hemorrhage in a patient on oral anticoagulants. Acta Neurol Belg 94: 35-43, 1994

9) Nozaki, I, MatsumotoY, Yamaguchi K, Shimizu Y, Kumahashi K, Munemoto S: A case of lumbar myxopapillary ependymoma discovered due to headache. Clin Neurol 53: 136-142, 2013 (Japanese)

10) Oertel J, Gaab MR, Piek J: Partial recovery of paraplegia due to spontaneous intramedullary ependyma haemorrhage. Acta Neurochir (Wien) 142: 219-220, 2000

11) Rivierez M, Oueslati S, Philippon J, Pradat P, Foncin JF, Muckensturm B, Dorwling-Carter D, Cornu P. Ependymoma of the intradural filum terminale in adults. Neurochirurgie 36: 96-107, 1990

12) Ulrich CT, Beck J, Seifert V, Marquardt G: Ependymoma of conus medullaris presenting as subarachnoid haemorrhage. Acta Neurochir (Wien) 150: 185-188, 2008

13) Schweitzer JS, Batzdorf U: Ependymoma of the cauda equina region: diagnosis, treatment, and outcome in 15 patients. Neurosurgery 30: 202-207, 1992

14) Tait MJ, Chelvarajah R, Garvan N, Bavetta S: Spontaneous hemorrhage of a spinal ependymoma: a rare cause of acute cauda equina syndrome: a case report. Spine 29: E502-E505, 2004

15) Barone BM, Elvidge AR: Ependymomas: a clinical survey. J Neurosurg 33: 428-438, 1970

16) HogenEsch RI, Staal MJ: Tumors of the cauda equina: the importance of an early diagnosis. Clin Neurol Neurosurg 90: 343-348, 1988

17) Mork SJ, Loken AC: Ependymoma: a follow-up study of 101 cases. Cancer 40: 907-915, 1977

18) Sonneland PR, Scheithauer BW, Onofrio BM: Myxopapillary ependymoma: a clinicopathologic and immunocytochemical study of 77 cases. Cancer 56: 883-893, 1985

19) Greenberg M: Handbook of Neurosurgery, 5th ed. New York: Thieme, 2001, pp. 482-483

20) Tait MJ, Chelvarajah R, Garvan N, Bavetta S: Spontaneous hemorrhage of a spinal ependymoma: a rare cause of acute cauda equina syndrome. Spine 29, E502-E505, 2004

21) Patten J. Neurological differential diagnosis, 2nd ed. London: Springer, 1996, pp. 266-268

22) Rawlings CE 3rd, Giangaspero F, Burger PC, Bullard DE: Ependymomas: a clinicopathologic study. Surg Neurol 29: 271-281, 1988

23) Dijindjian M, Djindjian R, Houdart R, Hurth M: Subarachnoid hemorrhage due to intraspinal tumors. Surg Neurol 9: 223-229, 1978

24) Martinez-Perez R, Hernandez-Lain A, Paredes I, Munarriz PM, Castaño-Leon AM, Lagares A: Acute neurological deterioration as a result of two synchronous hemorrhagic spinal ependymomas. Surg Neurol Int 3: 33, 2012

25) Nicastro N, Schnider A, Leemann B: Anaplastic medullary ependymoma presenting as subarachnoid hemorrhage. Case Rep Neurol Med 2013: 701820, 2013

26) Khalatbari MR, Moharamzad Y: Myxopapillary ependymoma of the conus medullaris presenting with intratumoral hemorrhage during weight lifting in a teenager. Childs Nerv Syst 30: 181-183, 2014

27) Tonogai I, Sakai T, Tezuka F, Goda Y, Takata Y, Higashino K, Sairyo K: Spontaneous rupture and hemorrhage of myxopapillary ependymoma of the filum terminale: a case report and literature review. J Med Invest 61: 430-435, 2014

28) Fincher EF: Spontaneous subarachnoid hemorrhage in intradural tumors of the lumbar sac. J Neurosurg 8: 576-584, 1951

29) Garcia DM: Primary spinal cord tumors treated with surgery and postoperative irradiation. Int J Radiat Oncol Biol Phys 11: 1933-1939, 1985

30) Sasanelli F, Ordesi G, Campo B, Mariani G: Altered bladder function as the only and late presenting symptom of ependymoma of the filum terminale. Ital J Neurol Sci 8: 387-389, 1987

31) Nakamura M, Ishii K, Watanabe K, Tsuji T, Matsumoto M, Toyama Y, Chiba K: Long-term surgical outcomes for myxopapillary ependymomas of the cauda equina. Spine (Phila Pa 1976) 34: E756-E760, 2009

32) Feldman WB, Clark AJ, Safaee M, Ames CP, Parsa AT: Tumor control after surgery for spinal myxopapillary ependymomas: distinct outcomes in adults versus children: a systematic review. J Neurosurg Spine 19: 471-476, 2013 